\title{
The Trans-Canadian Excursion of the British Association and the International Mathematical Congress.
}

THE Toronto meetings of the British Association and the International Mathematical Congress in August were followed by an excursion from that city to Vancouver and Victoria and back. About 360 persons took part in it, mainly members of the Association from Great Britain, but including about two dozen members of the International Mathematical Congress from European countries, and a few Canadians and Americans. The excursion was generally voted a wonderful success and a most enjoyable and memorable experience. From a collection of notes and impressions from various sources, it is now possible to visualise something of its wide scientific interest.

The outward journey passed through the mining and agricultural districts of northern Ontario, and proceeded, by way of Winnipeg, Saskatoon, and Edmonton, to Vancouver, following the route of the Canadian National Railway, with the exception of a stage in northern Ontario on that of the Timiskaming and Northern Ontario Railway. The return journey from Vancouver was made over the Canadian Pacific Railway through the famous mountain scenery of British Columbia, and by Calgary, Regina, Fort William and Port Arthur, and Sudbury, to Toronto. The whole excursion represented 5396 miles of travel by rail; it lasted from August I7 until September 4, for almost the whole of which period the two special trains were the dwelling-places of the travellers, and the comfort of the provision made for them by the two great railways is attested by the absence of expressions of distaste for this mode of life, the habit of which was soon acquired. Moreover, the timetable of the excursion was arranged with extraordinary skill in regard to viewing points of interest, passing quickly over stages of least scenic attraction, and affording reasonable periods for rest. The generosity of provincial governments and the local committee in Toronto rendered it possible to make the journey at exceptionally cheap rates.

The excursion offered a measure of scientific interest in every department, though perhaps geologists, botanists, zoologists, and agriculturists found the widest scope. Quite apart from formal arrangements, botanists and entomologists were most conspicuous in their activities whenever the trains stopped at station or crossing, and it was possible, for however brief a period, to get out of them; the freedom of the Canadian railways in this respect was appreciated by all as a mere relaxation from travel, but it also afforded real opportunities for collecting. The economic and industrial activities of the provinces traversed; the inhabitants and conditions of life in town and country; the architectural and other developments in the greater cities, especially as realised by those who had previously visited themthese features, together with the natural beauties of the Dominion, afforded sufficiently varied interest for all the trains' company, and an enlargement of their scientific horizon. Nothing impressed the visitors more than the lavish ground-plans and beautiful buildings erected for such institutions as the Universities of Saskatchewan at Saskatoon and Alberta at Edmonton, and the Manitoba Agricultural College near Winnipeg, to which must be added the new site and designs for the University of British Columbia.

With these developments in view, it can scarcely be mere accident that the reception of the party in the visited cities differed materially from that encountered in 1909 , when an excursion to the West was made after the Winnipeg meeting. Be it said at once, the high quality of Canadian hospitality does not vary. But the phase of speeches confined to words of welcome and imperial sentiment (things however admirable in themselves), the phase of frank confession that science and its aims were not understood, the phase of the triumphal areh and the town band-these seem to have passed away. Instead, the party on the present occasion was received with words which indicated a real appreciation of its mission; the scientific problems which are most closely allied with Canadian progress were clearly pointed out, and visiting scientific workers were invited to inspect and participate in the results of Canadian research. From every principal stoppingpoint came requests for some form of scientific communication from members of the party, and in two instances, as will be seen, there were actual sessions of some of the Sections of the Association.

Parties of geologists and botanists left Toronto in advance of the main body, to spend additional days in northern Ontario in investigation respectively of the mineralogy and the forest and plant phenomena of that region. The main body viewed the mines and process of extraction at Cobalt, Kirkland Lake, and Timmins, and the power plant and paper mills at Iroquois Falls, with its " garden city " separated by many miles of forest from any other considerable centre of population. Agriculturists left the trains at Cobalt for a short run by motor-car through a portion of the "clay belt," to view the recent extension of farming there and to visit the Dominion Experimental Farm. At Swastika, some of the members of the Anthropological Section called upon a family of Londoners, whose improved circumstances since emigration greatly impressed them.

At Winnipeg, Man., nearly the whole party was entertained at the Manitoba Agricultural College; economists and others visited the grain exchange; a geological party went to Stony Mountain to study the Upper Ordovician rocks of the district, and a party of engineers and others was taken to the municipal hydro-electric plant at Point du Bois, 78 miles from the city, incidentally viewing some interesting features of Galician and other settlement in the district.

At Saskatoon, Sask., proceedings began with the formal opening of the new chemistry building in the University of Saskatchewan. Sectional sessions then took place, in chemistry with a discussion on photosynthesis, in zoology and agriculture jointly on the subject of animal diseases, and in geology. Agricultural and experimental grounds and stockyards, the clay deposits of the neighbourhood, and other features of scientific interest were seen, and members interested in overseas settlement saw something of the homes of the people. In the evening a public lecture was given by Dr. E. E. Slosson on photochemistry and modern civilisation.

At Edmonton, Alta., there were sessions of the Sections of Physics, Geology, and Botany and Agriculture (jointly). Special geographical, geological, and agricultural parties were formed to see things of particular interest to them. In the evening a public meeting was held in the convocation hall of the University; when addresses were delivered by Sir John Russell, Sir William Beveridge, and Dr. J. S. Flett. Some of the botanists left the main excursion at Edmonton for a journey by motor-car through central Alberta and thence into the mountains, rejoining the rest at Banff.

NO. 2873 , VOL. I I 4 ] 
The main excursion, after leaving Edmonton, called at the mountain resort established by the Canadian National Railway in Jasper Park, where the members were guests of Sir Henry Thornton, general manager of the railway. At Vancouver and Victoria, a most interesting and varied programme was arranged. Stanley Park, the Fraser lumber mills, the Capilano Canyon, a settlement of Squamish Indians on the north side of the harbour, the beautiful fiord of Howe Sound, with the Britannia copper mines above it, and the power plant at Lake Buntzen were among the points visited from Vancouver by members concerned with their several scientific interests; while at Victoria the astrophysical and meteorological observatories, the museum, some old Indian village sites, and the beauties of Butchart's Gardens and the gardens of Government House, with several localities of botanical interest, were inspected. A number of lectures were given in Vancouver at public meetings or to societies and clubs, the speakers including Prof. G. W. O. Howe on radio-telegraphy, Dr. A. W. Borthwick on forestry, Prof. W. T. Gordon on gem stones, Prof. W. W. Watts on buried landscape, Dr. and Mrs. Shrubsall on physical and mental welfare, and Dr. Ivy Mackenzie on physiological discoveries of importance to the man in the street. The president, Sir David Bruce, met members of the Vancouver Medical Association. Mr. O. H. T. Rishbeth gave a lecture on modern geography at New Westminster. Marine biologists visited the well-known station at Nanaimo.

Three beautiful days were spent on the mountain section of the Canadian Pacific Railway, with calls at Glacier, Lake Louise, and Banff, and ample opportunity, thanks to the provision of open observation cars, to view the scenery between these points. A small party paid a private visit to the ranch of H.R.H. the Prince of Wales, near High River, Alta. The main party called at Calgary, Alta., where the oil refineries and other industrial establishments were seen, and at Regina, Sask., where addresses were delivered by Prof. D'Arcy Thompson, Sir Thomas Holland, and Dr. Marion Newbigin. From Kenora, Ont., trips were made on the Lake of the Woods, the limnologists working tow-nets and the geologists examining some of the islands. At Fort William and Port Arthur, the twin ports at the head of Lake Superior, arrangements for handling the grain export from the west were shown, and a geological party viewed the interesting features of Mount M'Kay and the vicinity. Brief opportunities for further field work were afforded by halts on the fine northern coast of Lake Superior, and the scientific investigations of the journey ended with the inspection of nickel and copper mines at Sudbury, Ont.

In this short narrative, no specific reference has been made to the generous hospitality extended to the travellers at every point by public bodies and private individuals. Luncheons and dinners, always admirably arranged, afforded an opportunity for general intercourse which was impossible in the dining-cars; and fleets of private motor-cars were placed at the disposal of the visitors in every city. All who took part in the excursion owe unqualified gratitude to its organisers and to those who made them their guests.

\section{Pigments, Varnishes, and Building Stones. ${ }^{1}$}

\section{Early Methods of Oil Painting.}

THE evidence to be obtained from ancient manuscripts as to early methods of oil painting has been re-examined. From this it is clear both from the manuscript of Theophilus and the manuscript of Eraclius that the properties of such drying oils as linseed oil and walnut oil were thoroughly understood so early as the twelfth century, if not earlier, and their preparation in a suitable condition for a painting medium and their use for this purpose.

The methods used in their preparation differ very little from the best practice of to-day. The refining and bleaching of the oil and the use of driers was well understood, and there was no indication in passing from these earlier recipes to those of the fifteenth century that any new discovery of importance was made at the time of the brothers Van Eyck. Passing to later times, Vasari directs that pigments are to be ground in walnut oil or linseed oil, and this is all that is necessary, and he recommends the use of walnut oil as less liable to darken with time.

Many recipes for varnishes are given, and as neither spirits of turpentine nor alcohol were available in commercial quantities until the end of the fifteenth century, these varnishes are what we should now describe as oil varnishes, consisting of resins dissolved in hot oil. The natural balsams of the pine, resin, mastic, and sandarac, often all mixed together, were used in their preparation, the proportion of resinous material to oil being very high, and the varnishes consequently being very sticky and having to be heated and rubbed on with the hand. Spirit varnishes corresponding to the mastic varnishes of to-day are found in the sixteenth-century and later recipes.

The evidence of the accounts preserved at Ely and

${ }^{1}$ From lectures delivered on November $\mathrm{I}_{2}, \mathrm{I}_{3}$, and $\mathrm{x}_{9}$ in a course of six lectures to the students of the Royal Academy, London, by Prof. A. P. Laurie, professor of chemistry at the Academy.
Westminster shows that both oil and varnish were used in painting on walls during the thirteenth and fourteenth centuries, this being the northern tradition, while the Italian tradition was the use of egg as a medium. There is no indication in these recipes of any special secret differing from what we know to-day; but it has been suggested by Prof. Berger and others that the early method of painting in the fifteenth century may have been with an emulsion of varnish or oil with yolk or white of egg, and two recipes, one in a Venetian manuscript of the fourteenth century and one in a Bolognese manuscript of the fifteenth century, are quoted in support of this theory.

It may be admitted that if these early painters wished to paint in varnish instead of in oil, they would have had to blend the varnish with white or yolk of egg to make it into a workable medium, and the question is worthy of further inquiry.

These early pictures were painted on a wood panel sometimes covered with strips of linen and coated with a gesso made of parchment size and whitening or plaster of Paris which had been soaked in water until it lost its binding properties. Recent experiments carried out by Mr. Thompson at the HeriotWatt College, Edinburgh, on an old sixteenth-century panel, have revealed the fact that this panel was coated with a non-absorbent gesso upon which a very thin layer of absorbent gesso was laid, so as to ensure the binding of the oil to the surface of the gesso and, at the same time, preserve from staining the pure white surface of the gesso below. On this pure white gesso panel the picture was drawn in detail, and laid out either in monochrome or partly in colour with pigments probably mixed with size, and upon this the pigments ground in oil or, it may be, an emulsion of varnish and egg were laid, care being taken to paint the high lights very thinly as compared with the rest of the picture. In course of time the oil yellows and

$$
\text { No. } 2873 \text {, VOL. I I } 4 \text { ] }
$$

